REVISTA X, Curitiba, volume 14, n.4,p. 87-106, 2019

\title{
A LINGUAGEM NÃO-BINÁRIA NA LÍNGUA PORTUGUESA: POSSIBILIDADES E REFLEXÕES MAKING HERSTORY ${ }^{1}$
}

The genderqueer language in Portuguese: possibilities and reflections making herstory

\author{
Héliton Diego LAU - UFPR ${ }^{2}$ \\ Gabriel Jean SANCHES - UFPR ${ }^{3}$
}

\begin{abstract}
RESUMO: Este trabalho tece uma reflexão acerca de uma nova forma de linguagem aplicada na língua portuguesa em que, ao contrário das práticas empregadas no discurso, referidas aos sujeitos, uma forma que não marque exclusivamente um gênero binário. Ao comentar sobre essa linguagem, advinda de pessoas que não se auto identificam com o binário de gênero, os pronomes da língua portuguesa podem não os representar. Ao comentar sobre ela, faremos uso dessa marca de linguagem, portanto, trazemos uma perspectiva rizomática (DELEUZE \& GUATTARI, 1995) para essa reflexão, assim como abordagens dos Letramentos Múltiplos (LEANDER \& BOLDT, 2012; MASNY, 2012) e do Letramento Crítico (JORDÃO, 2013) em uma apresentação performativa e subversiva (BUTLER, 2013).
\end{abstract}

PALAVRAS-CHAVE: Linguagem não-binária; Performatividade; Rizoma; Letramento Crítico; Letramentos Múltiplos.

\begin{abstract}
This present study proposes a reflection on a new form of language applied in the Portuguese language in which, practices employed usually marks a binary gender in most part of the words used. While presenting it in this study, we will make use of this, because there is no escape to reflect on it without its use. In this paper, we present a rhizomatic perspective (DELEUZE \& GUATTARI, 1995) for this reflection, as well as approaches of Multiple Literacies (LEANDER \& BOLDT, 2012; MASNY, 2012) and Critical Literacy (JORDÃO, 2013) in a performative and subversive way (BUTLER, 2013).

KEY-WORDS: Genderqueer language; Performativity; Rhizome; Critical Literacy; Multiple Literacies.
\end{abstract}

\section{É POSSÍVEL UM COMEÇO?}

Nossa reflexão é acerca de uma problematização na linguagem quando marca um determinado gênero na língua portuguesa (LP) em que, ao contrário do que se

\footnotetext{
${ }^{1} \mathrm{O}$ presente trabalho foi realizado com apoio da Coordenação de Aperfeiçoamento de Pessoal de Nível Superior - Brasil (CAPES) - Código de Financiamento 001.

${ }^{2}$ Doutorando em Letras pela Universidade Federal do Paraná, na área de Estudos Linguísticos. Membro do grupo interinstitucional de pesquisa Estudos do Texto e do Discurso: Entrelaçamentos Teóricos e Analíticos (UFPR-UNICENTRO). E-mail: heliton.diego@ hotmail.com

${ }^{3}$ Mestre em Letras pela Universidade Federal do Paraná, na área de Estudos Linguísticos. Membro do Grupo de Pesquisa em Línguas Estrangeiras Modernas (GPLEM-UFPR) e docente da Universidade Estadual do Paraná, campus Paranaguá. E-mail: hampshirelocks@ hotmail.com
} 
REVISTA X, Curitiba, volume 14, n.4,p. 87-106, 2019

emprega, como apenas "todos", "todas", por exemplo, no discurso, refira-se a sujeitos, sem marcar exclusivamente um gênero binário (feminino ou masculino), mas um que fuja da norma, por exemplo: “tod@ s”, “todxs”. Ao refletir sobre essa linguagem nãobinária (LAU, 2018), é impossível deixar de usá-la, haja vista que por meio de uso que se observa os sujeitos nela inseridos, como ocorreu mediante entrevista com uma pessoa não-binária. Portanto, faremos uma "dublagem" trazida para este trabalho a partir de uma perspectiva rizomática (DELEUZE \& GUATTARI, 1995), assim como abordagens do Letramento Crítico (JORDÃO, 2013), Multiletramentos (LEANDER \& BOLDT, 2012) e sobre a Teoria dos Letramentos Múltiplos (MASNY, 2012).

\section{SHE DONE ALREADY DONE HAD HERSES}

A divisão que segue este trabalho será performativa, vindo de uma interpretação subjetiva acerca do conceito explanado por Butler (2013) e influenciados pelos bordões de RuPaul do reality show: RuPaul's Drag Race, competição que busca eleger em cada temporada a drag queen que possui carisma, singularidade, ousadia e talento. Os bordões utilizados por RuPaul farão parte do nosso trabalho pela forma como o reality show é desenvolvido. O motivo pela escolha dessa forma de aplicabilidade será exposto ao longo da reflexão.

Este título acima faz parte do discurso falado por RuPaul, apresentadora do programa, em que as drag queens se reúnem para ouvir uma pequena introdução e "pistas" do que serão desafiadas durante a semana, tal como ocorre no reality show. Esses desafios incluem apresentações ao vivo, montagens de vários looks que pertençam a temática proposta pela apresentadora etc. Aqui, posicionamo-nos como a apresentadora para darmos uma "pista" sobre o que virá:

- Como pensar numa linguagem que não marque um gênero binário específico, mas que possibilite a leitura oral?

- Como RuPaul traz, de início, uma questão/reflexão enigmática, aproximamo-nos disso para a discussão.

\section{GENTLEMEN, START YOUR ENGINES, AND MAY THE BEST WOMAN, WIN!}

Como é um discurso que inicia os desafios, as montagens de looks para o desafio final, preparamos quem for ler este trabalho para o que está por vir. De agora em diante, 
posicionamo-nos como as drag queens do programa apresentando a linguagem nãobinária e o conceito de performatividade.

\section{Uma língua(gem) para quem?}

A finalidade primordial da linguagem não-binária (LNB) é "trazer uma reflexão acerca do binarismo presente na LP e a dificuldade de pessoas que não se identificam com o binário de gênero (homem x mulher) nas formas escrita e falada" (LAU, 2018, p. 13). Uma das línguas oficiais do Brasil - a LP - não possui um "gênero neutro", pois nela se nota essa "caixinha binária", porque falamos $o$ copo, $a$ televisão, por exemplo. Ou seja, marcamos o gênero masculino e o feminino em tudo. Nessa mesma perspectiva, não faz exceção quando se refere às pessoas. A LP diferencia e dicotomiza tudo em masculino e feminino. Por outro lado, se houvesse esse "gênero neutro" na LP, as pessoas que não se identificam com os pronomes binários se identificariam com o "neutro" ou se sentiriam diminuídas pelo teor desta terminologia?

Com esse avanço da LNB na língua inglesa (SALTZBURG \& DAVIS, 2010), um novo pronome de tratamento foi criado: o pronome "Mx." (pronuncia-se "mux" ou “mix"), que é o "neutro" de "Mr." (senhor) e "Mrs." (senhora), sem uma tradução oficial para a LP.

$M x$ (noun): A title used before a person's surname or full name by those who wish to avoid specifying their gender or by those who prefer not to identify themselves as male or female: 'the bank is planning to introduce the honorofic ' $M x$ ' as an alternative for anyone who feels that they don't, for reasons of undetermined gender, fit into being either a Mr, Mrs, Miss or a Ms' (OXFORD online).

A língua inglesa, em sua própria estrutura, não marca especificamente um gênero binário em todas as palavras apesar que as desigualdades se materializam de várias outras formas, como remuneração diferenciada pelo gênero, por exemplo. A palavra teacher para falantes de LP deverá ser traduzida de duas formas: professora e/ou professor. Há casos em que a palavra muda conforme o gênero, ainda numa perspectiva binária, como actor/actress. O pronome they já é utilizado na forma singular, também já dicionarizado, como um pronome neutro, já que somente se traduz para a LP duas possibilidade oficializadas: "ela"/"ele".

They (pronoun): 1 [third person plural] Used to refer to two or more people or things previously mentioned or easily identified. 'the two men could get life sentences if they are convicted'. 1.1 People in 
general. 'the rest, as they say, is history'. 1.2 Informal: People in authority regarded collectively. 'they cut my water off'. 2 [singular third person plural] Used to refer to a person of unspecified gender. 'ask a friend if they could help' (OXFORD online).

Considerando o dicionário como instrumento que dá legitimidade para a língua(gem) enquanto sistema, é necessário problematizar o ensino de língua inglesa, pensando na realidade brasileira, especialmente na formação de profissionais da educação em que haja essa problematização/reflexão da língua inglesa como "neutra", para assim traçar possíveis rupturas no binarismo da LP. Ainda sobre essa questão do dicionário que visa possuir vários recortes como validação hegemônica, concordamos com a questão da legitimação a partir do uso, sendo a dicionarização consequência da língua que é viva.

Moita Lopes (2013) utiliza o sinal arroba (@) como um gesto político para marcar uma possível "equidade de gênero" na linguagem, não focando somente no masculino, nem no feminino, mas mostrando algo que seja válido para esses dois gêneros.

Do ponto de vista dos falantes e escritores, as variações ideológicas da linguagem são importantes porque acabam influenciando as mudanças linguísticas. As ideologias linguísticas de variação de gênero, por exemplo, têm cada vez mais forçado em círculos feministas (e para além dele) o uso de escolhas lexicais no português como "o ser humano" ou "as pessoas", em contextos nos quais no passado se usaria "o homem" para se referir à espécie humana. Da mesma forma, muitas feministas têm preferido, o uso de "el@" para evitar o uso de "ele(a)" ou o mais comum "ele" para se referir ao ser humano (MOITA LOPES, 2013, p. 20).

Esse sinal pode ser utilizado e ter sua validade, porém, é inviável para a pronúncia. A segunda língua oficial do país, a Língua Brasileira de Sinais (Libras), amparada pelo Decreto 5.626, de 22 de dezembro de 2005, que regulamenta a Lei $n$. 10.436, de 24 de abril de 2002, "em que possui gramática e estrutura própria e seu sistema linguístico de natureza visual-motora" (BRASIL, 2002), utiliza esse sinal gráfico na tradução para o alfabeto romano. Deixamos claro que Libras é língua e não linguagem, pois possui estrutura e gramática próprias, o que difere do "português sinalizado", ou seja, não se utiliza a estrutura gramatical da LP (LAU, 2015, 2018).

A Libras possui uma forma de escrita própria chamada Sign Writing (SW), contudo, ainda não é muito utilizada em espaços acadêmicos. A forma mais recorrente é a glosa (sistema de anotação) que utiliza palavras da LP em maiúsculas para se “aproximar" da Libras, segundo Streiechen (2013), quando há a marcação de gênero na 
palavra, utiliza-se @. Por exemplo: “(EU) SURD@”. Na forma de glosas não dá para saber exatamente qual gênero é para se ler essa palavra; por outro lado, se for escrita em SW, fica dessa forma:

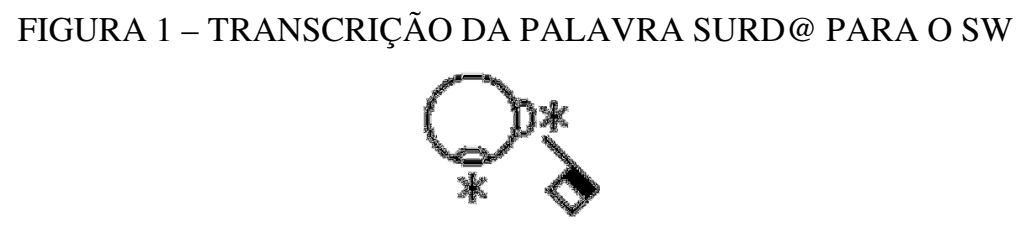

Fonte: (LAU, 2018)

Tanto na forma de glosas como em SW não sabe-se explicitamente qual gênero a palavra SURD@ está marcando. Para a palavra se tornar SURDO, é preciso a marcação de gênero masculino, assim como para SURDA. "Na Libras, a indicação de gênero é marcada sempre pelo sinal de 'HOMEM' ou 'MULHER' antecedido do sujeito" (STREIECHEN, 2013, p. 73, ênfase nossa). Aqui já notamos uma importante diferença do sistema linguístico da Libras e da LP: só saberemos o gênero binário da palavra se ele for marcado antes; sem isso, a palavra se mantém "neutra"; diferente da LP que, na forma escrita/falada é marcada ao final da palavra de forma feminina ou masculina, sendo que a forma masculina tem um prestígio social maior e é utilizada como "generificador" nos discursos.

FIGURA 2 - TRANSCRIÇÃO DA PALAVRA
HOMEM PARA O SW

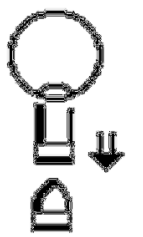

Fonte: (LAU, 2018)
FIGURA 3 - TRANSCRIÇÃO DA PALAVRA MULHER PARA O SW

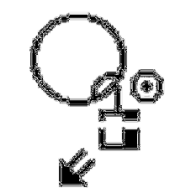

Fonte: (LAU, 2018)

Trazendo esse contraste, percebemos a importância da marcação de um gênero que fuja da norma para visibilidade de pessoas trans não-binárias (n-bs), por isso o pronome "elu":

[...] por um ato político, para mostrar que o pronome considerado "neutro" em nossa sociedade exclui as pessoas não-binárias, já que elus não se veem como homens nem como mulheres, portanto, não faz sentido para estus a utilização do "neutro "eles", assim como o feminismo trata esta questão (LAU, 2018, p. 14). 
REVISTA X, Curitiba, volume 14, n.4,p. 87-106, 2019

\section{Performatividade}

Butler $(2007,2013)$ nos apresenta o conceito de performatividade que significa o comportamento que aprendemos e, consequentemente, copiamos da sociedade; "formas" de como ser homem e mulher. Porém, quando o sujeito que se identifica como homem tem atração por outro homem, veste roupas consideradas femininas, "fura" essa performance, fazendo com que as demais pessoas tentem encaixá-lo no feminino para "suprir" essa fuga.

A grande preocupação da autora é tentar pensar o modo como a palavra "gênero" vai sendo usada por váries autories da filosofia, da psicanálise e o modo como isso vai reorganizado a maneira como as pessoas pensam o sexo, como uma questão biológica e sexualidade e identidade de gênero como questões culturais e sociais. É nesse mapeamento que Butler (2013) está tentando mostrar que, principalmente as autoras da década de 60 e 70, vão aproximando a ideia de gênero de uma ideia mais biológica, associando mais gênero a ideia de sexo. Para tentar explicar um pouco mais essa questão, ela ressignifica o conceito de performatividade a partir de Austin (1962), que, de fato, uma identidade de gênero é aprendida, como se ela fosse repetida no cotidiano, à medida que as pessoas vão aprendendo umas com as outras.

[...] a performatividade deve ser compreendida não como um "ato" singular ou deliberado, mas, ao invés disso, como a prática reiterativa e citacional pela qual o discurso produz os efeitos que ele nomeia. [...] as normas regulatórias do "sexo" trabalham de uma forma performativa para constituir a materialidade dos corpos e, mais especificamente, para materializar o sexo do corpo, para materializar a diferença sexual a serviço da consolidação do imperativo heterossexual (BUTLER, 2007, p. 154).

A respeito das normas regulatórias do sexo, fica evidente que Butler (2007) não exclui o aspecto biológico, mas o tenciona com as questões socioculturais, por isso a distinção entre gênero enquanto identidade e sexo como aspecto biológico.

A categoria do "sexo" é, desde o início, normativa. [...] o "sexo" não apenas funciona como uma norma, mas é parte de uma prática regulatória que produz os corpos que governa, isto é, toda força regulatória manifesta-se como uma espécie de poder produtivo demarcar, fazer, circular, diferenciar - os corpos que ela controla. Assim, o "sexo" é um ideal regulatório cuja materialização é imposta: esta materialização ocorre (ou deixa de ocorrer) através de certas práticas altamente reguladas. Em outras palavras, o "sexo" é um construto ideal que é forçosamente materializado através de uma reiteração forçadas destas normas (BUTLER, 2007, 153-154). 
Assim, podemos considerar que "sexo", nesta questão, é algo atribuído à natureza, que é controlado, regulado e normatizado pelo corpo. Esse cistema ${ }^{4}$ dita normas sobre esse corpo. Porém, segundo Butler (2007, 2013), por mais que haja essa regularidade dos corpos, ela não é nunca completa. Havendo as instabilidades, essa lei regulatória acaba se voltando contra o próprio cistema. Dessa forma, é possível refletir na problematização dos corpos cis e trans. Por exemplo: por que é falado que uma mulher trans quando aplica silicone está deformando seu corpo, sendo que esse mesmo discurso não é voltado à mesma prática feita pela mulher cis? (LAU, 2018).

A autora também fala sobre a performatividade utilizando como exemplo a drag queen:

A performance do (sic) drag brinca com a distinção entre a anatomia do (sic) performista e o gênero que está sendo performado. [...] ao imitar o gênero, o (sic) drag revela implicitamente a estrutura imitativa do próprio gênero - assim como sua contingência. Aliás, parte do prazer, da vertigem da performance, está no reconhecimento da contingência radical da relação entre sexo e gênero diante das configurações culturais de unidades causais que normalmente são supostas naturais e necessárias. No lugar da lei da coerência heterossexual, vemos o sexo e o gênero desnaturalizados por meio de uma performance que confessa sua distinção e dramatiza o mecanismo cultural da sua unidade fabricada (BUTLER, 2013, p. 196-197, ênfase da autora).

Ao mostrar o conceito de perfomatividade com a drag queen, nota-se que o que entendemos por feminino e masculino, numa questão identitária de gênero, é uma construção que foi naturalizada, pois ao mostrar um corpo biologicamente masculino com adereços femininos, rompe a norma, ainda mais que a drag queen se apropria de adereços considerados femininos e exagera, mostrando que a partir do exagero é possível notar/questionar a construção social do que é considerado feminino e masculino.

Tendo isso como base para sustentação do nosso trabalho, apoiados na questão da LNB, questionamos: o uso da LNB neste trabalho não seria um "exagero" a se pensar na construção que a gramática normativa considera a língua enquanto cistema?

\footnotetext{
${ }^{4}$ Adotamos esta forma de escrita para fazer um jogo de palavras com as questões de gênero. Cisgênero é a pessoa que se identifica com seu gênero imposto ao nascimento por condição da genitália. É uma palavra antônima de/para transgênero/transexual. Dessa forma, segundo Silva (2004), a partir da teoria queer, estamos queer (homossexual, mas também "diferente") e não straight (heterossexual, mas também "quadrado").
} 
REVISTA X, Curitiba, volume 14, n.4,p. 87-106, 2019

\section{CATEGORY IS...}

Adentramos na passarela para o desfile, já costurades com o que Lau (2018) e Butler $(2007,2013)$ nos propõe. As drag queens montam seus looks para o desfile com base em um tema proposto por RuPaul; da mesma forma, elencamos tema(s) para aprimorarmos nosso look teórico, afinal, como já diz RuPaul na música Born Naked: "We're all born naked, and the rest is drag",.

\section{Por que o Letramento Crítico?}

Descobrimos no Letramento Crítico (LC) justificativas mais do que plausíveis para refletir sobre o uso da LNB na LP, pois a proposta dessa abordagem fundamentada em pressupostos teóricos consiste em ter consciência de nossas escolhas linguísticas perante seu uso social. Nossa tentativa de aliar o LC com a LNB lança possibilidades para uma prática que abra fronteiras que podem ir além dos contextos em que atualmente a LNB existe e é utilizada. Teorias advindas com o pós-estruturalismo permitem que façamos uma leitura mais subversiva de nossas realidades e possamos refletir de maneira mais crítica sobre a forma como atuamos no mundo e com o mundo. É por entender que a língua está em transformação constante que percebemos a urgência em trazer à tona discussões sobre gênero para dentro da linguagem e como ela se dá.

Nosso objetivo com essa “dublagem”, vestir essa roupa que é o LC dentro desse texto, se dá com o interesse em questionar as relações de poder na LP e o quanto ela pode acabar sendo excludente se não pensarmos em medidas emergenciais de inclusão. Jordão (2010, p. 73), ao falar de LC em um contexto educacional afirma que "língua é discurso, espaço de construção de sentidos e representação de sujeitos e do mundo". Os sentidos não são "dados" por uma realidade independente do sujeito: eles são construídos na cultura, na sociedade e, portanto, na língua. É partindo dessa reflexão crítica que nos vestiremos, no decorrer deste trabalho, de LC "da cabeça aos pés" na tentativa de ressignificar o LC para uma perspectiva de linguagem e uso social, pois entendemos que:

O letramento crítico busca engajar o aluno em uma atividade crítica através da linguagem, utilizando como estratégia o questionamento das relações de poder, das representações presentes nos discursos e das implicações que isto pode trazer para o indivíduo em sua vida e comunidade (MOTTA, 2008, p. 38).

\footnotetext{
${ }^{5}$ Todes nós nascemos pelades e o resto é drag (tradução nossa).
} 
Ao utilizar a LNB não estamos apenas propondo mudar nossa visão a respeito da língua, mas ao propor essa mudança estaremos também dando visibilidade e legitimando práticas que até então não eram vistas por grande parte da sociedade. Com isso em mente, buscamos dentro deste trabalho questionar e problematizar a LP e sua construção binária que de certa forma "exclui" outros contextos de fala que não representa parte da sociedade que hoje vem ganhando visibilidade por meio das redes sociais e, mais do que nunca, precisa de representatividade por meio da língua também.

Outro conceito muito importante dentro do LC é a identidade, pois somos múltiplos, atuamos dentro de diversos segmentos e grupos sociais: família, trabalho, escola etc.; e dentro de cada uma atuamos com uma identidade diferente ou identidades múltiplas, por isso, agir criticamente nesses contextos significa saber empregar o uso consciente de determinadas expressões e não outras. Isso também tem relação com a performatividade (BUTLER, 2007, 2013). Jordão (2010, p. 76) afirma que "a multiplicidade de sentidos possibilitada pelas diversas ideologias é tida como algo produtivo: ao invés de uma realidade por trás de uma ideologia perniciosa, temos muitas verdades construídas ideologicamente e partilhadas socialmente”. Como, por exemplo, ao utilizar a LNB dentro de contextos específicos estamos demonstrando um reconhecimento acerca da legitimidade de seu uso para aquelus que ela vem representar, e fazendo isso com criticidade possibilitaria uma maior aceitação de pessoas que antes se sentiriam constrangidas e excluídas pela estrutura da LP.

Há uma necessidade quase urgente em se refletir criticamente sobre a posição que ocupamos socialmente.

O mundo globalizado contemporâneo traz consigo a aproximação e justaposição de culturas e povos diferentes - muitas vezes em situações de conflito. [...] se todas as partes envolvidas buscassem ler criticamente suas posturas, procurando compreender suas próprias posições e a de seus adversários, haveria a possibilidade de transformar confrontos violentos e sangrentos (MENEZES DE SOUZA, 2010, p. 130).

Pensando nisso, acreditamos que utilizar a LNB faria parte de uma construção crítica acerca do uso da linguagem, pois todas as partes envolvidas a utilizariam, não somente uma determinada camada da sociedade. Dessa forma, evitaríamos algum tipo de exclusão de gênero em nossa fala em contextos específicos.

Apoiamos nosso texto nas reflexões de Freire (2005) sobre a relações entre "palavra" e "mundo" quando ele diz que não podemos ter uma "leitura ingênua" 
baseada no senso comum, tomando para si significados dados, naturais e incontestáveis e propõe que tenhamos ao invés de um saber "ingênuo" um saber mais "rigoroso" e analítico através de uma reflexão crítica, já que é justamente nossa proposta neste trabalho.

Acreditamos que a linguagem é uma das armas mais poderosas dentro da sociedade e com ela podemos questionar as relações de poder; é através da linguagem também que podemos compreender quem somos no mundo pois, "as lutas pela igualdade e justiça podem ser alcançadas através da linguagem, pois assim os problemas podem ser expostos, contestados e, consequentemente, reconstruídos através da língua" (CERVETTI, 2001, p. 35, tradução nossa).

\section{Por que os Multiletramentos se fazem presentes neste trabalho?}

Escolhemos os Multiletramentos como parte de nossa vestimenta nessa "dublagem" por entender que, assim como Leander e Boldt (2012), o que colocam sobre texto, descrevendo que corpo e texto são um só, portanto, nossos gestos, atitudes, visões de mundo, são construídos na medida em que entramos em contato com diferentes tipos de textos, compreendendo então que textos podem ser verbais ou não verbais. É por meio desse contato que criamos nossa relação com o mundo e a partir disso fazemos relações entre a sociedade e nossas experiências mais pessoais. Outra questão que merece ser justificada nesse "look" é que les autories utilizam o rizoma como uma entrada para uma "rizoanálise", descrevendo o mundo e nossa relação como algo intrínseco que nos transforma.

\section{Por que a Teoria dos Múltiplos Letramentos?}

Nosso terceiro e último "look" metodológico é inspirado a partir de nossas leituras em Masny (2012) que, por meio do rizoma, oferece "entradas" para uma leitura de mundo e do texto que transformam nossas relações em sociedade.

Chamou-nos muito a atenção a forma rizomática para a geração de dados que busca interpretar como as coisas acontecem dentro de um contexto situado, busca entender como as coisas estão no mundo e atribuir sentido de maneira contingencial e situada. é dessa maneira que também fizemos nossa geração de dados para este trabalho. Buscamos apenas registrar o que tínhamos ao nosso alcance por meio de uma conversa com uma pessoa não-binária que se identifica como agênero, assexual e panromântico. 
Sobre a identificação dessa pessoa entrevistada, há vários "rótulos" 6 desconhecidos, pois as questões de gênero e sexualidade estão começando a ganhar visibilidade, assim como outras problematizações, como é o caso do nosso corpus. A começar pela identidade de gênero, que é como o sujeito se identifica, há duas formas possíveis: binária (homem ou mulher) ou não-binária (que há uma gama de identificações que diferem do masculino e feminino $)^{7}$, como no caso da identidade de gênero da pessoa que entrevistamos, que é agênero, ou seja, elu não se sente enquadrade em nenhum gênero, contrapondo com os gêneros binários, mas que pode se identificar "entre" eles. Já a orientação sexual delu é assexual, ou seja, não há atração sexual. Esse é um tabu da sociedade, pois estamos inserides em uma sociedade que hipersexualiza tudo e quando há pessoas que são assexuais acham "estranho" (lê-se “doentes"). Com o avanço dos estudos de gênero e sexualidade e problematizando a assexualidade com a alossexualidade, que são pessoas que têm atração sexual, abriram mais um pouco o leque "desmembrando", agora, a romanticidade, que, no caso da nossa pessoa entrevistada, é panromântica, ou seja, sente-se atraíde romanticamente por todos os gêneros.

\section{THE TIME'S CAME, FOR YOU TO LIP SYNC FOR YOUR LIFE! GOOD LUCK, AND DON'T FUCK IT UP!}

Montades com nossos looks teóricos, passamos agora para a dublagem que, no reality show, propõe uma música para as drag queens dublarem. Como drags da Linguística Aplicada, assumimos o papel de RuPaul em nos dar o desafio de “dublarmos" a geração de dados feita em uma "conversa" com uma pessoa não-binária que se identifica como agênero, assexual e panromântico nomeada neste trabalho como Jaloo. Com ajuda des autories será feita a dublagem.

Utilizaremos para nossa análise uma geração de dados rizomática, na tentativa de interpretar o que está dado, buscando entender como as coisas estão no mundo e atribuir sentido de maneira contingencial e situada buscamos registrar o que tínhamos ao nosso alcance sobre a LNB por meio de uma conversa com o sujeito já identificado mais acima.

\footnotetext{
${ }^{6}$ Entendemos que os "rótulos" dividem, separam, individualizam, mas, por outro lado, acreditamos que essa "rotulação" é política para entender melhor as identificações, expressões de gênero, sexualidade e romanticidade.

${ }^{7}$ Para mais informações, verificar o glossário de (expressões de) gêneros não-binários em Lau (2018).
} 
Seguindo a abordagem metodológica de Masny (2012), apresentamos nossa geração de dados por vinhetas. Esta se deu a partir de uma conversa via WhatsApp por entendermos que essa pode ser uma ferramenta valiosa para geração de dados a partir do rizoma, sob uma perspectiva aberta, sem começo, meio ou fim, como afirmam Deleuze e Guattari (1997), esse processo pode oferecer mais segurança para le entrevistade assim como trazer à tona uma reflexão sobre a LNB a partir das lentes de uma pessoa que a utiliza e dessa forma possa ser observada dentro de seu contexto específico.

Os letramentos consistem de palavras, gestos, atitudes, modos de ouvir, falar, escrever em formas humanas e não humanas, ou seja, modos de estar no mundo [...]. Os letramentos se fundem com religião, gênero, raça, cultura e poder e isso produz escritories, artistas, influenciadories digitais: comunidades. Os letramentos podem ser observados dentro de um contexto particular dentro do tempo e espaço em que eles operam (MASNY, 2012, p. p. 115-116, tradução nossa).

Para Masny (2012), não há como desvencilhar os letramentos da nossa vida cotidiana, ele está presente em nossos gestos, tem a ver com nossas atitudes e nossas escolhas. Nossa interação com máquinas humanas e não humanas (como GIFs, vídeos, imagens etc.), está diretamente ligada com as nossas percepções e visões de mundo, sendo essas que nos transformam constantemente. Portanto, os letramentos se fundem com os mais diversos aspectos de nossa vida, tais como gênero e linguagem que é foco da nossa análise.

Para a "rizoanálise" utilizaremos vinhetas e essa escolha se deu por entender que os significados já estão dados dentro desse grande rizoma e nossa tarefa seria apenas tentar descrevê-la e mostrar como a LNB atua dentro de espaços e contextos específicos e situados.

Nossa tentativa em descrever esse contexto situado contingencialmente parte da ideia de que independente do que está dado, "Nossa interpretação a respeito do que está sendo observado não encerra no texto, mas pode-se partir do texto para o mundo" (LEANDER \& BOLT, 2012, p. 42, tradução nossa). Com isso, apresentamos abaixo algumas vinhetas que serão utilizadas para análise neste trabalho.

\#1

P1: Jaloo, quais são os espaços em que a LNB pode ser vista e utilizada com mais frequência?

Jaloo: [...] Eu convivo muito com pessoas trans, mas com pessoas trans n-bs a minha convivência se dá especificamente pela internet, ou 
seja, no meu cotidiano eu uso bastante a linguagem neutra para se referir a elus, para ter conversas com elus, mas se dá na internet, ou seja, através do chat do Facebook, WhatsApp, de outros aplicativos de comunicação. Pessoalmente, eu não tenho convivências com outras pessoas n-bs, então, não chega sequer ser necessário a utilização, porque eu não tenho essa convivência [...].

É observado que a LNB, denominada por Jaloo de "linguagem neutra", é utilizada em ambientes específicos, ou seja, somente entre pessoas trans n-bs. Podemos contrastar essa utilização da LNB com a linguagem utilizada por pessoas da comunidade gay, em que as gírias utilizadas por essa comunidade se dão, em maior grau, quando há o espaço para utilização, o que não impede o seu uso por outras comunidades, como mulheres cis-héteros, por exemplo (LAU, 2015).

Podemos interpretar que a não utilização da LNB por não ter convivência pessoalmente não traz visibilidade e apaga/silencia essa comunidade, pois é uma linguagem que nasceu do espaço e da necessidade dessas pessoas buscarem resistência/visibilidade pela linguagem. O espaço que estamos inserides permite (ou não) falar sobre determinadas coisas (FOUCAULT, 2010). É interessante problematizar essa utilização (ou não) no espaço acadêmico para problematização/reflexão sobre a LNB, seu uso em textos acadêmicos, utilização na forma oral durante a aula pode(rá) ser utilizada ou não e se o espaço, entendendo este espaço com docentes preparades, dispostes e interessades a abrir esse espaço para reflexão. Não estamos fora das relações de poder. Ainda de acordo com o LC:

A produção de significação não é um ato aleatório e voluntarioso de indivíduos independentes: pelo contrário, a produção de significação é um ato complexo sócio-histórico e coletivo no que cada produtor de significação pertence simultaneamente a diversas e diferentes comunidades que constituem um conjunto social coletivo (MENEZES DE SOUZA, 2011, p. 136).

Ou seja, a forma como usamos a linguagem está intrinsecamente ligada com o contexto onde estamos inserides e a questão que pode gerar reflexão é se a comunidade docente (re)conhece essa linguagem e estão dispostes a utilizá-la em seus espaços contribuindo para a construção de sentido a partir da LNB dentro dos espaços em que atuam e se comunicam.

\#2

P2: Existe variação de pronomes dependendo do contexto de utilização ou a LNB deve ser usada sempre? 
Jaloo: Pois é, uma coisa nesse ponto que é bom também já de apontálo logo cedo, é de que não existe uma convenção completamente determinada de como funciona essa linguagem neutra/n-b. Então, como não existe acaba sempre ficando por escolha da pessoa como se referir. O que eu posso dizer é que como eu percebo que diferentes pessoas usam. Eu percebo, por exemplo, pessoas que usam, se referem, fazem uso da linguagem neutra especificamente e apenas com pessoas $n-b$, que pedem pelo pronome neutro. Então, porque no nosso português, de uma certa forma, o masculino é usado como neutro na questão do plural, né? Ou seja, se a gente tá no ambiente que tem várias mulheres, mas tem um homem, você usa o masculino. Fala "todos", fala "eles"; se tiver só mulher vai falar "elas". Existem pessoas que quando exigisse esse plural, gosta de usar o neutro pra justamente pela ideia de que mesmo que possa não tendo uma pessoa que peça por pronomes neutros lá ao usar a linguagem neutra ela não vai estar priorizando um gênero sobre o outro. Então, têm pessoas que utilizam dessa forma, mas nesse exemplo que você disse, por exemplo, de num contexto em que as pessoas podem não saber, eu acho que acaba dependendo muito da sua intenção, porque, por exemplo, você pode usar a linguagem n-b [...].

Quando Jaloo aponta que "não existe uma convenção completamente determinada de como funciona essa linguagem neutra/n-b", a problematização acerca dela fica aberta e, ao mesmo tempo, contraditória.

Le entrevistade afirma, no início, que a utilização da LNB se dá quando se refere exclusivamente à pessoas trans n-bs, por visibilidade e reconhecimento dessas pessoas na sociedade através da língua(gem), como apontado no início do trabalho, na língua inglesa há reconhecimento. Ou seja, marca um gênero específico, pois a questão ideológica apontada por elu, no início dessa vinheta, é a (r)existência de pessoas n-bs na língua(gem).

Em seguida, elu aponta a questão da LP em que o masculino é o gênero "neutro", porém, o movimento feminista luta pela igualdade também na língua(gem) trazendo o feminino a frente pela questão da igualdade de gênero; a mesma questão se aplica no uso da linguagem utilizada na internet e defendida por Moita Lopes (2013), o uso do arroba e, mais atualmente, o do "x", sem uma marcação específica. O problema é que nenhum abarca as pessoas n-bs, o que não causa o desmerecimento do movimento feminista.

Se pensarmos a língua como discurso e ela se dá/se faz como prática social, essa possui carga ideológica. Por isso a abertura para problematização da LNB como discurso e enquanto prática social. Jaloo menciona sobre o uso da LNB na forma plural, diferente da gramática normativa. Pensando dessa forma, há um acolhimento maior e a visibilidade de pessoas n-bs no seu uso linguístico, porém, a luta do movimento 
feminista é apagada quando se utiliza somente o "todes", por exemplo, numa forma de inclusão "total".

Quando enunciamos "todos" é importante frisar que é uma marca que, em tese, abarca grande parte, porém, como já comentado mais acima, os letramentos também trazem outras questões além da linguagem, como gênero, classe, sexualidade, por isso a importância da problematização do uso da linguagem de uma forma geral $e$ específica no seu uso. "Todos", quando enunciado, tem gênero, classe, sexualidade e raça marcada exclusivamente, bem como "todas e todos". É possível pensar o uso do "todes", com essas mesmas problemáticas, tendo em vista que a língua por parte da gramática e seu uso social que acolhe somente pronomes binários tenha essa marca?

\#3

P2: Como é a recepção da utilização da LNB por pessoas trans n-bs e a sociedade em geral?

Jaloo: [...] Eu vejo as pessoas usando a linguagem neutra dessa forma quando elas estão num ambiente que geralmente se discute temas LGBT, temas sobre gênero, porque geralmente as pessoas são mais familiarizadas e se elas não estão familiarizadas elas têm interesse, provavelmente elas têm interesse em estarem familiarizadas, mas em contextos mais cotidianos mesmo em que você lidar com pessoas que não discutem ou são muito novas nesse assunto fica muito difícil de você usar porque você pode acabar sendo alvo de chacota, a linguagem acaba sendo um alvo de chacota porque da forma que ela é demonstrada por pessoas que não tem muito conhecimento sobre essa discussão, aí acaba criando essa chacota da linguagem n-b, da pessoa n-b. [...] Existem pessoas que usam a linguagem neutra como uma forma de não impor um gênero a pessoa quando ela não sabe o gênero da pessoa, ou seja, a gente sempre assume o gênero de uma pessoa quando a gente olha pra ela, o que é normal, mas as vezes a pessoa se expressa de uma forma ambígua que você não quer apontar, você não quer impor um gênero aí você se refere à ela usando a linguagem neutra, até o momento que você descobre de alguma forma como aquela pessoa se identifica e quer ser tratada.

Novamente Jaloo traz no seu discurso o espaço de utilização da LNB, porém, com algumas "restrições", pensando em formas de como as pessoas ouvem/utilizam a LNB não a utilizem como forma depreciativa, por exemplo, utilizando o "e" e o "u", e sim como formas que pessoas n-bs encontraram na LP de tentar marcar uma certa visibilidade, como ato de (r)existência, porém, algumas pessoas podem utilizar desse discurso das pessoas n-bs e deslegitimar seu uso com "piadas" (lê-se violências) com a pessoa n-b, como "linguagem do 'e", em que todas as palavras da LP em que há "o" ou “a” seja substituídas por "e". 
REVISTA X, Curitiba, volume 14, n.4,p. 87-106, 2019

Como linguistas aplicades preocupades com a educação, pensamos na importância da discussão das questões de gênero e sexualidade atreladas ao campo da Linguística Aplicada, pois são temas transdisciplinares que podem perpassar por diversas áreas, não ficando presos somente à Pedagogia, por exemplo.

Uma forma de utilização que Jaloo menciona é a questão da LNB ser utilizada quando não saber qual gênero a pessoa se identifica numa conversa, não levando em conta primordialmente os aspectos biológicos do corpo da pessoa, como seios. “[...] uma pessoa que tem seios, geralmente será vista/lida pela sociedade como mulher, porque ninguém parou para pensar que uma pessoa que tem seios é apenas uma pessoa que tem seios, como a sociedade dispõe de mulheres que não possuem uma vagina, e sim um pênis" (LAU, 2018, p. 22, ênfase do autor).

Nessa vinheta é interessante observar um outro funcionamento da LNB: para não marcar especificamente um gênero, como faz os pronomes da LP.

\section{ALL RIGHT, JUST BETWEEN US, RUPAUL INPERSONATORS, WHAT DO YOU THINK?}

É o discurso em que a apresentadora usa quando as drag queens saem da passarela e ela se reúne com les jurades para falar da performance. Nesta seção, assumimos a posição delus para comentar sobre nossa "dublagem" feita anteriormente.

Ao observar a questão que a LNB traz, é interessante reportar a questão da sexualidade em que Foucault (1988) desconstrói o discurso sobre a natureza da sexualidade, como se ela fosse inata, propõe um rompimento, comparando, ironicamente, a sexualidade do Oriente com a do Ocidente; em que na primeira o povo possuía uma ars erotica: "Na arte erótica, a verdade é extraída do próprio prazer, encarado como prática e recolhido como experiência [...]" (FOUCAULT, 1988, p. 57). Já para o Ocidente, a prática é a scientia sexualis: “[...] só a nossa desenvolveu, no decorrer dos séculos, para dizer a verdade do sexo, procedimentos que se ordenam, quanto ao essencial, em função de uma forma de poder-saber rigorosamente oposta à arte das iniciações e ao segredo magistral, que é a confissão" (FOUCAULT, 1988, p. $58)$.

Enquanto o Oriente observava a sexualidade como prazer, o Ocidente tomou o sexo apenas como ciência com ajuda da confissão, pois era a partir do sujeito confessando seus desejos. A partir disso, o autor cria um dispositivo da sexualidade, ou seja, os discursos sobre os Aparelhos Ideológicos de Estado sobre a sexualidade, 
instância de organização produzindo diversos discursos que enunciam condições de verdades sobre o sujeito, nesse caso, a medicina, em que o homem casado sentir atração pelo vizinho, por exemplo, ia-se "patologizar" como praticante do "homossexualismo", tendo em vista que a partir do século XIX “criou-se” a homossexualidade e, através dos discursos sobre ela, a desvalorização desta e, por consequência, a heterossexualidade como norma.

Com isso, Butler (2013) traz a investigação da desnaturalização do gênero, ou seja, "a tarefa dessa investigação é centrar-se - e descentrar-se - nessas instituições definidoras: o falocentrismo e a heterosexualidade compulsória” (BUTLER, 2013, p. 9).

A autora trata do gênero como construção social, puramente. Quer dizer, o paradigma sexo-gênero-corpo-desejo sustenta-se nessa lógica de que os opostos se atraem e de que o sexo é dado e o gênero é impresso pela sociedade. É isso que significa acerca da heterossexualidade compulsória: é quando a pessoa que dispõe de um útero gera uma criança e, novamente, a medicina, a partir da genitália, a classifica como "menina" ou "menino", por isso o sexo é dado, diferente do gênero, que é como o indivíduo se identifica com as construções sociais do que significa "ser homem" e "ser mulher”, através da ideia da performatividade. Há uma dissociação sexo x gênero através da convenção histórico-cultural.

Consideremos a interpelação médica que apesar da emergência recente das ecografias, transforma uma criança, de um ser "neutro" em um "ele" ou em uma "ela": nessa nomeação, a garota torna-se uma garota, ela é trazida para o domínio da linguagem e do parentesco através da interpelação do gênero. Mas esse tornar-se garota da garota não termina ali; pelo contrário, essa interpelação fundante é reiterada por várias autoridades, e ao longo de vários intervalos de tempo, para reforçar ou contestar esse efeito naturalizado. A nomeação é, ao mesmo tempo, o estabelecimento de uma fronteira e também a inculcação repetida de uma norma (BUTLER, 2007, p. 161, ênfase da autora).

Partindo de uma perspectiva de "língua como invenção colonial" (MAKONI \& PENNYCOOK, 2007), as línguas seguem um modelo inventado para favorecer interesses particulares da hegemonia, o que de certa forma traz um apagamento no âmbito linguístico de outras manifestações sociais. Dessa forma, podemos concluir que a LNB traz visibilidade para uma comunidade que de certa forma é apagada na língua devido a questões que provém ainda dessa visão colonialista de língua, que, "não são discursos neutros, mas sim constitutivos de um paradigma da modernidade, enraizados em uma perspectiva cristã e/ou iluminista de leitura e compreensão do mundo" 
(SEVERO, 2017, p. 5). Esse paradigma vem dessa ideia de colonialidade e exploração, controle de terras, povos e línguas, que quando detalhados e descritos. Ainda hoje há essa ideia de que a língua é um sistema fixo que deve apenas servir como base para a elaboração de nossos discursos, mas que acaba desconsiderando os contextos discursivos onde os sujeitos estão inserides e, que dentro de cada comunidade, essa linguagem pode variar. As pessoas são construídas via linguagem:

\begin{abstract}
Enquanto uma abordagem estruturalista veria as estruturas ligadas a gênero como uma consequência do gênero binário enquanto realidade social, abordagens pós-estruturalistas vão além de uma relação meramente reflexiva entre realidade e linguagem e ressalta o papel dos usuários de uma língua como reguladores ativos das estruturas discursivas. A pergunta então não é muito quem é representade (ou não) a língua e sim como elas são construídas via linguagem, por exemplo, sendo masculino, feminino ou neutro. O termo "mecanismo de controle" tem sido usado para descrever esse fenômeno da linguagem utilizada para regular as realidades sociais (MOTSCHENBACHER, 2013, p. 247, tradução nossa).
\end{abstract}

Como estamos filiades a uma construção rizomática, nosso trabalho não terá um "fim" explicitamente. Ainda trabalhando com os discursos de RuPaul, após a conversa com jurades, ela fala: "Silence, I've made my decision! Bring back, my girls", Nessa parte do reality, RuPaul faz críticas positivas e negativas às queens, sendo que, ao final, uma é eliminada e a outra permanece na competição. Para a queen que permanece na competição ela diz: "Shantay, you stay!"; e para a eliminada: "Sashay, away!". Então, para nós, ao utilizarmos dos discursos do reality, esperamos que quem for ler nosso trabalho, aja como RuPaul e enuncie "Shantay, you stay!" e/ou "Sashay, away!" para a nossa reflexão feita aqui, juntamente com alguns questionamentos:

- A língua seria um cistema e a linguagem performativa?

- Quando o sujeito enuncia "bom dia a todas e todos" ou "bom dia a todos" ou "bom dia a todes", por exemplo, seria sua inscrição/posicionamento como sujeito em seu lócus enunciativo?

- Quando a LNB é utilizada fora de seus espaços ela abre o espaço para se discutir sobre o tema?

\title{
RUFERENCES ${ }^{9}$
}

\footnotetext{
8 "Silêncio! Já tomei minha decisão. Tragam de volta, minhas garotas" (tradução nossa).

${ }^{9}$ Como todo o trabalho foi escrito com base nos discursos de RuPaul, fizemos um trocadilho nesta parte utilizando o nome da drag queen.
} 
AUSTIN, John Langshaw. How to do thing with words: the William James lectures delivered at Harvard University in 1955. New York: Oxford University Press, 1962.

BRASIL. Lei n. 10.436, de 24 de abril de 2002. Dispõe sobre a Língua Brasileira de Sinais - Libras e dá outras providências. Diário Oficial da República Federativa do Brasil. Brasília, 25 de abril de 2002.

BUTLER, Judith. Corpos que pesam: sobre os limites discursivos do "sexo". In: LOURO, Guacira Lopes (org.). Pedagogias da sexualidade. 2 ed. Belo Horizonte: Autêntica, 2007, p. 151-172.

BUTLER, Judith. Problemas de gênero: feminismo e subversão da identidade. Tradução de Renato Aguiar. 6 ed. Rio de Janeiro: Civilização Brasileira, 2013.

CERVETTI, Gina.; PARDALES Michael; \& DAMICO, James S. A tale of differences: comparing the traditions, perspectives, and educational goals of critical reading and critical literacy. Reading Online, v. 4, n. 9, abr. 2001. Disponível em: <https://goo.gl/vAa3U6>. Acesso em 21 nov. 2017.

DELEUZE, Gilles; GUATTARI, Félix. Mil platôs: capitalismo e esquizofrenia, v. 1. Tradução de Aurélio Guerra Neto e Célia Pinto Costa. Rio de Janeiro: Ed. 34, 1995.

FOUCAULT, Michel. A história da sexualidade I: a vontade de saber. Tradução de Maria Thereza da Costa Albuquerque e J. A. Guilhon Albuquerque. Rio de Janeiro: Edições Graal, 1988.

FOUCAULT, Michel. A ordem do discurso: aula inaugural no Collége de France, pronunciada em 2 de dezembro de 1970. 20 ed. São Paulo: Loyola, 2010.

JORDÃO, Clarissa Menezes. Abordagem comunicativa, pedagogia crítica e letramento crítico - farinhas do mesmo saco? In: HILSDORF ROCHA, Cláudia; MACIEL, Ruberval (orgs.) Língua estrangeira e formação cidadã: por entre discursos e práticas. Campinas: Pontes, 2013, p. 69-90.

LAU, Héliton Diego. A (des)informação do bajubá: fatores da linguagem da comunidade LGBT para a sociedade. Temática, v. 11, n. 2, p. 90-101, fev. 2015. Disponível em: <https://goo.gl/6iMHGm>. Acesso em: 10 ago. 2017.

LAU, Héliton Diego. Pelo direito e orgulho de ser heterossexual no terceiro domingo de dezembro. São Paulo: Pimental Cultural, 2018.

LEANDER, Kevin; BOLDT, Gail. Rereading “A Pedagogy of Multiliteracies”: Bodies, Texts, and Emergence. Journal of Literacy Research, v. 45 , n. 1, p. 22-46, dez. 2012.

MASNY, Daiana. Multiple literacies theory: discourse, sensation, resonance and becoming. Discourse: studies in the cultural politics of education, v. 33, n. 1, p. 113-128, fev. 2012.

MENEZES DE SOUZA. O professor de inglês e os letramentos no século XXI: métodos ou ética? In: JORDÃO, Clarissa Menezes; MARTINEZ, Juliana Zeggio; 
HALU, Regina Célia. Formação "desformatada": práticas com professores de língua inglesa. Campinas: Pontes, 2011.

MOITA LOPES, Luiz Paulo da. Ideologia linguística: como construir discursivamente o português no século XXI. In: MOITA LOPES, Luiz Paulo da. Português no século XXI: cenário geopolítico e sociolinguístico. São Paulo: Parábola, 2013, p. 18-31.

MOTTA, Aracelle Palma Fávero. O letramento crítico no ensino/aprendizagem de língua inglesa sob a perspectiva docente. Disponível em $<\mathrm{https} / / / g o o . g l / t B w t G c>$. Acesso em 03 dez. 2017.

OXFORD. English Oxford Living Dictionaries. Disponível em: $<$ https://goo.gl/J8Bwxn>. Acesso em: 7 set. 2017.

SALTZBURG, Susan; DAVIS, Tamara S. Co-authoring gender queer youth identities: discursive telling and retellings. Journal of Ethinic and Cultural Diversity in Social Work, London, v. 19, n. 2, p. 87-108, 2010.

SILVA, Tomas Tadeu da. Documentos de identidade: uma introdução às teorias do currículo. 2 ed. Belo Horizonte: Autêntica, 2004.

STREIECHEN, Eliziane Manosso. Libras: aprender está em suas mãos. Curitiba: CRV, 2013. 